\title{
USO DA EDUCAÇÃO AMBIENTAL COMO FERRAMENTA-CHAVE NO PROCESSO DE RECUPERAÇÃO AMBIENTAL
}

\author{
Vicente Elício Porfiro Sales Gonçalves da Silva ${ }^{1}$ \\ Pollyana Maria Pimentel Monte ${ }^{2}$ \\ Sara Letícia Lopes de Souza Brito ${ }^{3}$ \\ Lucas da Silva ${ }^{4}$ \\ Maria Amanda Menezes Silva ${ }^{5}$
}

\begin{abstract}
RESUMO
O uso indisciplinado da terra é considerado a principal causa da degradação em todo o mundo, essa causa vai depender da forma como esse uso é realizado, bem como a finalidade e a resiliência do ecossistema impactado. Por ser um dos ecossistemas de terras secas mais diversificados do mundo, caracterizado por uma mistura de plantas lenhosas e herbáceas, com dominância de espécies florestais xerófitas e de folha caduca, a Caatinga sofre grande pressão pelo uso indisciplinado, apresentando altos índices de degradação. Diante disso, este trabalho buscou incorporar e analisar o papel da população nos processos de recuperação de áreas degradadas por meio da educação ambiental. Para isso, realizou-se uma mobilização no IFCE campus Quixadá, em quatro etapas abrangendo as etapas de uma recuperação ambiental: instruções, quebra de dormência, germinação, plantio e monitoramento. Conluiu-se que a população não tem o hábito de realizar tais práticas, mas tem bastante facilidade em assimilar os procedimentos. Além disso, conferiu-se a tamanha importância do monitoramento para o sucesso da recuperação.
\end{abstract}

Palavras-chave: Áreas Degradadas; Caatinga; Meio Ambiente; Restauração.

\footnotetext{
${ }^{1}$ Mestrando em Tecnologia e Gestão Ambiental e Graduado em Engenharia Ambiental e Sanitária, ambos pelo Instituto Federal de Educação, Ciência e Tecnologia (IFCE).

${ }^{2}$ Instituto Federal de Educação, Ciência e Tecnologia do Ceará - IFCE, campus Quixadá. ${ }^{3}$ Instituto Federal de Educação, Ciência e Tecnologia do Ceará - IFCE, campus Quixadá. ${ }^{4}$ Instituto Federal de Educação, Ciência e Tecnologia do Ceará - IFCE, campus Quixadá. ${ }^{5}$ Instituto Federal de Educação, Ciência e Tecnologia do Ceará - IFCE, campus Quixadá.
} 


\title{
USE OF ENVIRONMENTAL EDUCATION AS A KEY TOOL IN THE ENVIRONMENTAL RECOVERY PROCESS
}

\begin{abstract}
The undisciplined use of land is considered to be the main cause of degradation around the world, this will depend on how this use is carried out, as well as on the purpose and resilience of the impacted ecosystem. As one of the most diversified dryland ecosystems in the world, characterized by a mixture of woody and herbaceous plants dominated by xerophytic and deciduous forest species, the Caatinga is under great pressure due to undisciplined use, presenting high rates of degradation. In view of this, this work sought to incorporate and analyze the role of the population in the processes of recovery of degraded areas through environmental education. For this, a mobilization was carried out at the IFCE campus Quixadá, in four stages covering the stages of an environmental recovery: instructions, dormancy, germination, planting and monitoring. It was concluded that the population is not in the habit of performing such practices, but it is quite easy to assimilate the procedures. In addition, the importance of monitoring for the success of the recovery was given.
\end{abstract}

Keywords: Degraded Areas; Caatinga; Environment; Restoration.

\section{INTRODUÇÃO}

O crescimento populacional, o aumento nos padrões de vida da população emergente e $\mathrm{o}$ avanço das tecnologias frente a globalização, tem por consequência principal o uso excessivo dos recursos naturais (AMÉRICO et al., 2012; UYANIK, 2016). Como consequência principal destes processos, ocorre uma ampliação na geração de resíduos sólidos e um desleixo quase que total com o meio ambiente, tanto quantitativamente como em diversidade, especialmente nos conglomerados urbanos (MEDEIROS, 2015).

Ao falar em degradação ambiental, é imprescindível não salientar que o solo é o sistema mais afetado. Por ser um sistema vivo que é responsável pela estabilidade do meio ambiente, o solo é o elemento chave em diversas situações, principalmente na conservação de ambientes, ao manter a biodiversidade e a qualidade ambiental em larga escala, num paralelo com a disponibilidade de recursos (SALVATI et al, 2015).

Pode-se afirmar que hoje em dia, o índice de degradação do solo é um dos que mais tem despertado preocupação no âmbito global, visto que, diminui a qualidade do solo, principalmente nos parâmetros físicos, químicos e 
biológicos (FERRARA, SALVATI, TOMBOLINI, 2014; ITURRI et al., 2015). Essa degradação é induzida por questões socioeconômicas da sociedade, decorrentes de práticas industriais e crescimento urbano, que ao adotar práticas não sustentáveis, afetam drasticamente o solo (EMADODIN, NARITA, BORK, 2012; QUINTON, 2012; KHALEDIAN et al., 2016), sendo necessárias medidas de mitigação (CONSUEGRA, 2015).

A degradação do solo ocorre em maior intensidade e em larga escala principalmente em regiões semiáridas e de clima menos úmido, com poucas precipitações, forçando a população a utilizar cada vez mais o solo (ITURRI et al., 2015). Segundo Chaves et al. (2015) e Laplane et al. (2016), o semiárido brasileiro apresenta indicadores físicos e socioeconômicos bastante peculiares, que necessitam de tecnologias adequadas e facilitadoras do desenvolvimento sustentável da região. Estes autores apontam, ainda, que o desmatamento e a utilização inadequada das terras ocasionam a erosão dos solos, a deterioração e o esgotamento dos recursos naturais renováveis existentes, além de queda significativa da produção agropecuária. Tal fato ocorre não apenas em função do baixo nível de consciência conservacionista daqueles que atuam em determinado meio, mas em decorrência da ausência do conhecimento da capacidade de uso das terras e de sua aptidão agrícola.

No Brasil, a caatinga é uma floresta semiárida que ocupa aproximadamente $844.453 \mathrm{Km}^{2}$, o equivalente a $10 \%$ das terras nacionais (IBGE, 2010), sendo uma das florestas secas que tem maior biodiversidade no mundo (DOMBROSKI et al., 2010). No entanto, é pouco protegida e menos estudada, apesar de sua fragilidade (LEAL; PERINI, CASTRO, 2003).

Em meio a um cenário de clima semiárido caracterizado por altas temperaturas e um estresse hídrico refletido pelos baixos índices de precipitação, a caatinga apresenta inúmeras estratégias de sobrevivência como resposta ao meio na qual está inserida (ALVAREZ et al., 2012; SILVA, 2016). Tais condições ambientais são responsáveis por conferir uma alta taxa de evaporação com uma baixa capacidade de reter água (DOMBROSKI et al., 2010). Dessa forma, a degradação do solo, no âmbito da caatinga, acaba por piorar a situação ambiental em que se encontra, fazendo até mesmo com que muitos confundam degradação com característica típica de caatinga (CHAVES et al., 2015). 
De acordo com a finalidade do uso do solo, e da necessidade de preservação dos recursos naturais, é necessário o uso de estratégias de manejo adequadas para recuperação destes ambientes (CONSUEGRA, 2015). Assim, diversas pesquisas e experimentos têm sido realizados com o intuito de diminuir as taxas de degradação do solo. Dentre as pesquisas estão o uso de substratos com constante monitoramento (RODRíGUEZ, CAMPILLO \& MORAGA, 2015; GALES, 2016), isolamento geográfico (SILVA, 2016), valoração ambiental (OLIVEIRA \& SILVA, 2015) e práticas paralelas com a população local, assumindo que o uso de educação ambiental tem sido uma ferramenta indispensável para o sucesso da recuperação (CORTEZ-JUNIOR \& FERNANDEZ, 2016).

No Ceará, a degradação do solo ocorre principalmente devido a produção de lenha e carvão vegetal, uma vez que este desmatamento tem deixado a região semiárida do estado do Ceará cada vez mais vulnerável aos efeitos das mudanças climáticas, com forte tendência à desertificação, além de favorecer a erosão e assoreamento dos rios (ANDRADE \& ALMEIDA, 2012).

Para atenuar esse processo, são necessárias ações efetivas de recomposição das matas, através de árvores nativas da caatinga (AMERICO et al., 2012). Essas espécies nativas são naturalmente adaptadas à região de escassez hídricas e são muito importantes para o equilíbrio ambiental, favorecendo relações complexas com os demais seres vivos do ecossistema onde estão inseridas (SILVA, 2016).

Para que a recuperação seja efetivada de forma eficaz, são necessárias ações de mobilização ambiental, que consigam contribuir para a conscientização da população, ao induzir a preservação e recomposição de árvores nativas em áreas desmatadas, proporcionando uma melhor qualidade ambiental para a caatinga (ARAUJO \& SOUSA, 2011). A Educação Ambiental tem se tornado ferramenta indispensável para uma mudança na situação atual dos recursos naturais (SOUZA, 2013).

A Política Nacional de Meio Ambiente e a Constituição Federal brasileira, atribuíram ao Estado brasileiro que a garantia de um meio ambiente equilibrado deve acontecer através de práticas de Educação Ambiental. Dessa forma, este trabalho buscou incorporar uma comunidade nas etapas de recuperação ambiental em uma área experimental. Para isso, realizou-se uma 
mobilização de cunho educacional a respeito do tema, bem como participação e acompanhamento do público-alvo em todos os processos da recuperação, desde o planejamento até o monitoramento.

\section{METODOLOGIA}

\subsection{Descrição da área de estudo e das etapas}

O estudo foi realizado em quatro etapas principais. A primeira etapa aconteceu no Laboratório de Estudos Ecológicos e Ambientais do Bioma Caatinga (LEEABC) situado no Instituto Federal de Educação, Ciência e Tecnologia do Ceará - IFCE, campus Quixadá, em que o público-alvo pôde conhecer os conceitos referentes a recuperação de áreas degradadas e o seu papel nesse processo. Também no laboratório, a segunda etapa teve o intuito de apresentar as principais técnicas utilizadas para a quebra de dormência de espécies nativas da caatinga, fazendo-os realizar esta quebra para três espécies (Tabela 1), bem como realizar o preenchimento de sacos com substrato e a incorporação das sementes nestes sacos. No laboratório, o sistema de irrigação é automatizado e o viveiro conta com telas que retém $70 \%$ dos raios ultravioletas.

Tabela 1: Espécies e metodologia utilizadas para a quebra de dormência pelo público-alvo.

\begin{tabular}{|c|c|c|}
\hline NOME POPULAR & NOME CIENTIFICO & METODOLOGIA \\
\hline Angico-Vermelho & $\begin{array}{l}\text { Anadenanthera peregrina (L.) } \\
\text { Speg. }\end{array}$ & $\begin{array}{l}\text { Imersão em água à } \\
90^{\circ} \mathrm{C} \text { em banho maria } \\
\text { até estabilizar com } \\
\text { temperatura ambiente. }\end{array}$ \\
\hline Pau-Brasil & Caesalpinia echinata Lam. & $\begin{array}{l}\text { Imersão por } 20 \text { minutos } \\
\text { em ácido } \mathrm{H}_{2} \mathrm{SO}_{4} 98 \% \text {. }\end{array}$ \\
\hline Sabiá & Mimosa caesalpiniaefolia Benth. & $\begin{array}{l}\text { Escarificação } \\
\text { sementes nuas } \\
\text { ácido } \mathrm{H}_{2} \mathrm{SO}_{4} \quad 95 \% \text { por } \\
\text { cinco minutos. }\end{array}$ \\
\hline
\end{tabular}


A terceira etapa foi em campo, numa área experimental dentro da instituição (Figura 1), em que o público-alvo realizou o plantio de 180 mudas, divididas em nove parcelas sob a técnica de nucleação, com a diversidade de cinco espécies (Tabela 2). Em virtude da urgência do projeto, as mudas foram doadas pelo Jardim Botânico do Ceará, localizado em Caucaia, em parceria com a Secretaria de Meio Ambiente (SEMA) e o Projeto Biomas da EMBRAPA. Esta área experimental continha 323 metros quadrados e para que fosse realizado o plantio, houve uma limpeza total da área, eliminando toda e qualquer espécie invasora. As covas tinham aproximadamente 10 centímetros de largura e de profundidade.

A cidade de Quixadá apresenta clima Tropical Quente Semiárido, com temperatura em torno de 26 e $28^{\circ} \mathrm{C}$, e pluviosidade de aproximadamente $838,1 \mathrm{~mm}$ anuais, sendo as chuvas concentradas nos meses de fevereiro a abril (IPECE, 2015).

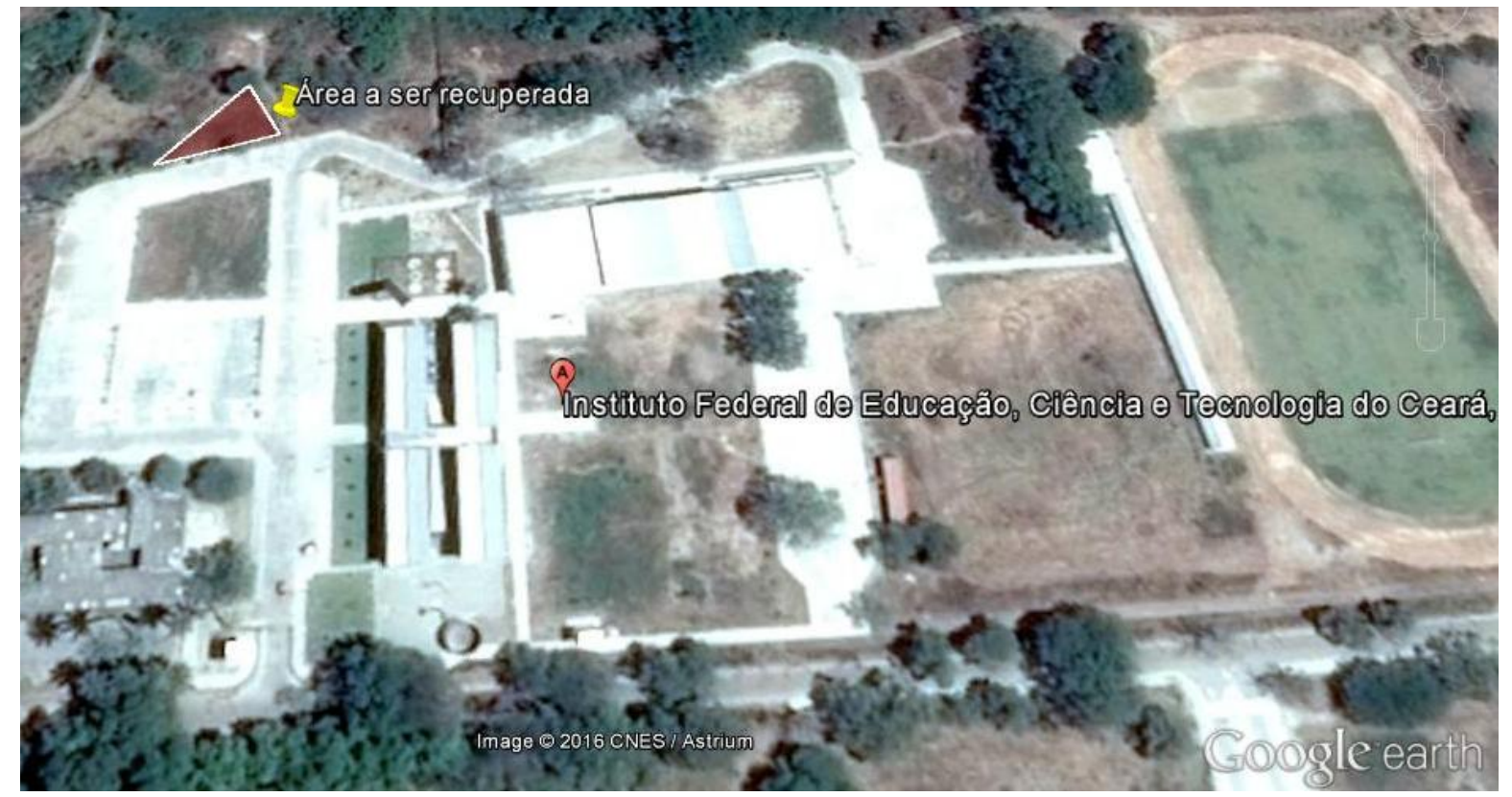

Figura 1: Localização da área experimental. Fonte: Google Earth (2016). 
Tabela 2: Espécies utilizadas no plantio.

$\begin{array}{ccc}\text { Nome Popular } & \text { Espécie } & \text { Quantidade } \\ \text { Angico-Vermelho } & \text { Anadenanthera peregrina (L.) } & 36 \\ \text { Speg. } & \\ \text { Sabiá } & \text { Mimosa caesalpiniaefolia Benth. } & 36 \\ \text { Jurema Preta } & \text { Mimosa tenuiflora Mart. } & 36 \\ \text { Jucá } & \text { Caesalpinia ferrea var. } & 36 \\ \text { Paineira } & \text { Ceiba speciosa (A. St.-Hil.) } & 36\end{array}$

Por fim, a última etapa do trabalho foi o monitoramento da área experimental e uma análise qualitativa do público-alvo em relação aos conhecimentos anteriores e posteriores ao trabalho. O monitoramento ocorreu por quatro meses após o plantio, tempo necessário para coletar informações do experimento paralelo e tempo mínimo para que os indivíduos plantados pudessem se estabilizar. Tal monitoramento ocorreu através de ações de acompanhamento de conformidade na área, tanto em relação ao sistema de irrigação por gotejamento que foi instalado, quanto em relação à retirada das espécies invasoras presentes no coroamento dos indivíduos plantados.

\subsection{Análise dos dados}

Ao todo, participaram da mobilização 40 pessoas tanto da comunidade local, quanto da comunidade acadêmica. Os dados referentes às etapas e aos conhecimentos prévios e adquiridos com esta mobilização, foram computados e analisados pelo software ASSISTAT, através de médias aritméticas simples e comparação por testes estatísticos.

\section{RESULTADOS E DISCUSSÃO}

\subsection{Caracterização do público-alvo}

Das quarenta pessoas que participaram da mobilização, 86\% correspondia à comunidade acadêmica, e o restante era referente à comunidade local. Esse fato comprova que a comunidade local não tem tanto interesse em se engajar nos projetos de recuperação de áreas, mesmo que 
estes projetos sejam para melhorar o ambiente em que essa comunidade se situa. Fato oposto ao encontrado em trabalhos realizados nessa própria área, em que mais da metade da população aponta a necessidade de projetos desse tipo e $67,33 \%$ afirmavam que ajudariam se houvessem projetos assim (SILVA \& GADELHA, 2016). No entanto, para que a recuperação alcance o sucesso esperado, é de suma importância a participação da população, principalmente a local, uma vez que esta colherá "os frutos" da qualidade ambiental e terá que ajudar no monitoramento.

\subsection{Primeira etapa}

A primeira etapa da mobilização aconteceu dentro do laboratório para que o público-alvo tivesse contato com os termos e conceitos utilizados em projetos de recuperação de áreas degradadas (Figura 2). Essa etapa ocorreu por meio de uma aula introdutória, onde houve a apresentação de definições e esboço do projeto por meio de uma exibição de slides. Cerca de $77 \%$ do público-alvo afirmaram desconhecer os conceitos e definições apresentados, e apenas $4 \%$ teve contato direto com projetos desse porte. No entanto, ao final desta etapa, houve $100 \%$ de satisfação e afirmaram que os conceitos serão fundamentais para a vida acadêmica e principalmente para a vivência em campo, buscando cada vez mais preservar o meio ambiente.

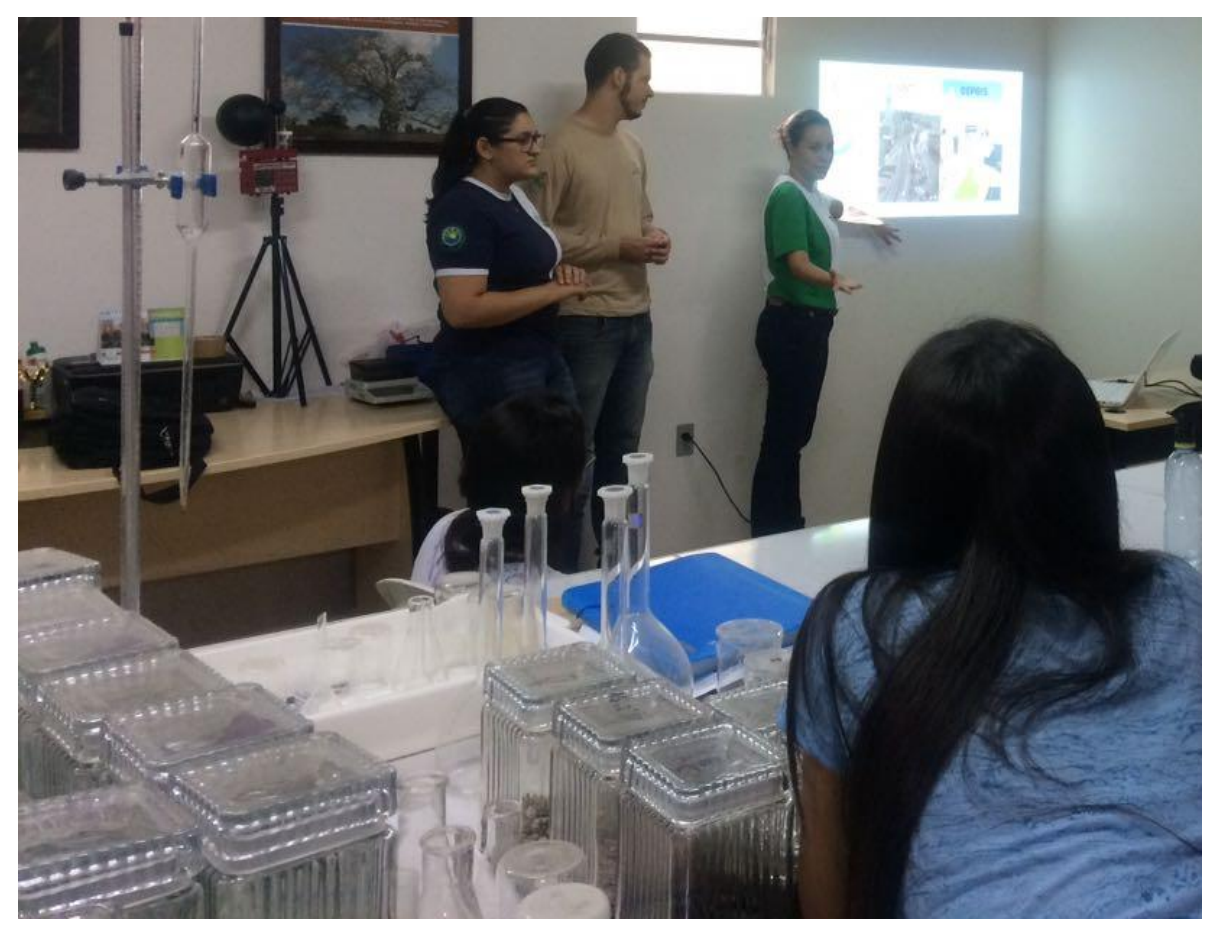


ISSN- 1413-8638

E-ISSN - 2238-5533

v. 23, n. 3, p. 252-266, 2018

Figura 2: Realização da primeira etapa da mobilização: Apresentação de conceitos e definições.

\subsection{Segunda etapa}

A segunda etapa da mobilização, também no laboratório, foi fundamental para o início da recuperação em si (Figura 3). Realizou-se a quebra de dormência de 60 sementes de três espécies da caatinga, nas quais houve a sobrevivência de $98 \%$. Isso comprova que a germinação dos indivíduos e a produção de mudas pode ser facilmente realizada por pessoas que não têm contato com estes procedimentos, visto que cem por cento do público-alvo nunca havia realizado quebra de dormência e produção de mudas.

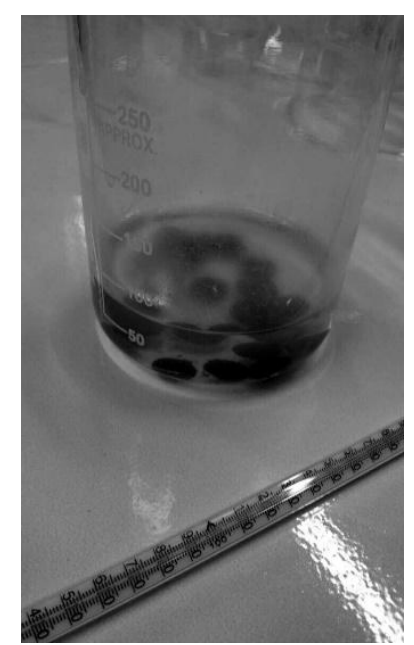

Figura 3: Quebra de dormência da espécie $A$. peregrina em água à $90^{\circ} \mathrm{C}$.

\subsection{Terceira etapa}

O plantio em campo foi realizado na terceira etapa da mobilização (Figuras 4 e 5). E todos que participaram afirmaram que irão realizar mais plantios como esse, pois acharam simples e de fácil execução. Dessa forma, espera-se que haja uma queda nos índices de áreas degradadas, uma vez que a população irá dispersar o conhecimento e contar com mais agentes multiplicadores de preservação ambiental. 


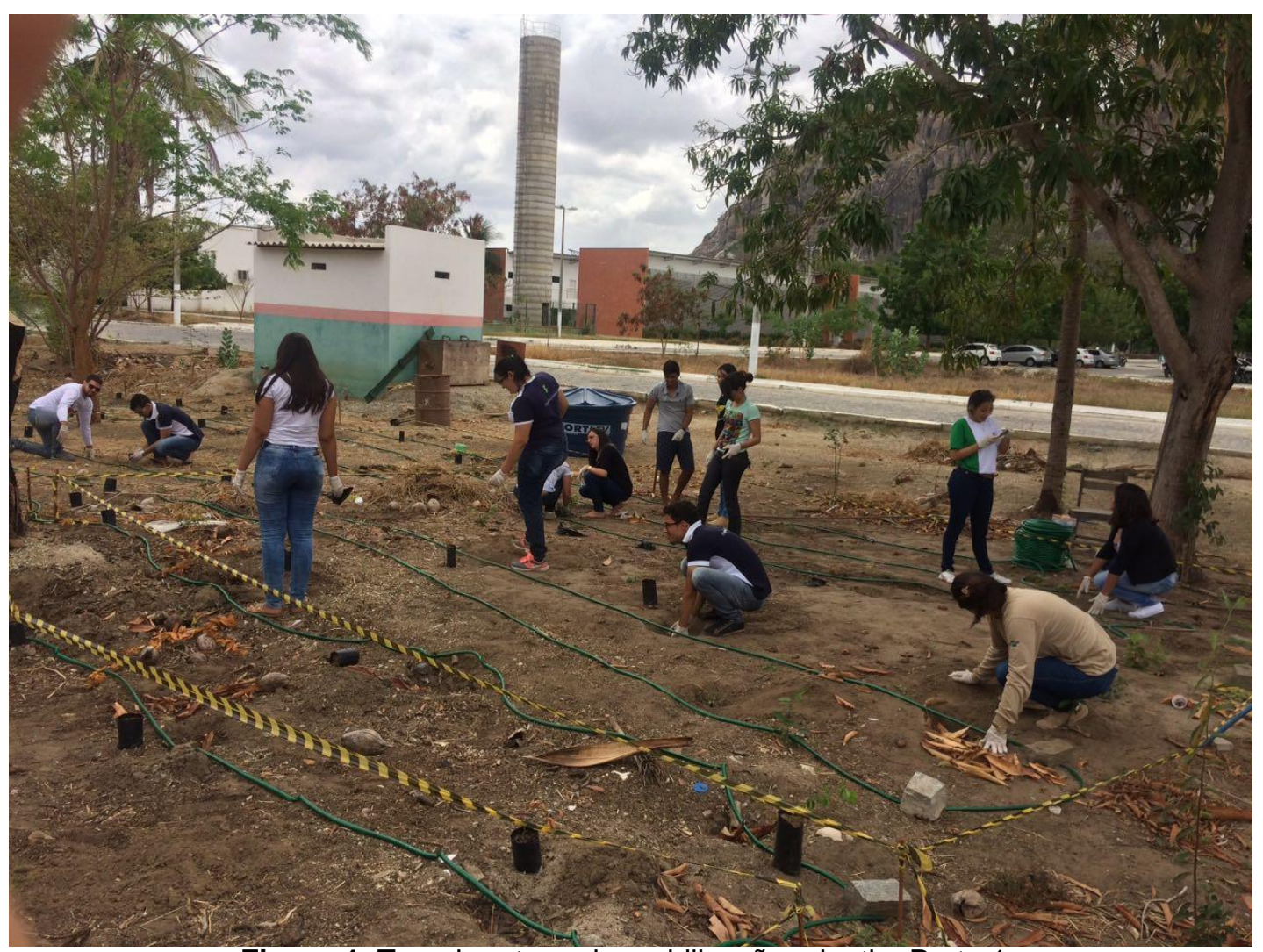

Figura 4: Terceira etapa da mobilização: plantio. Parte 1.

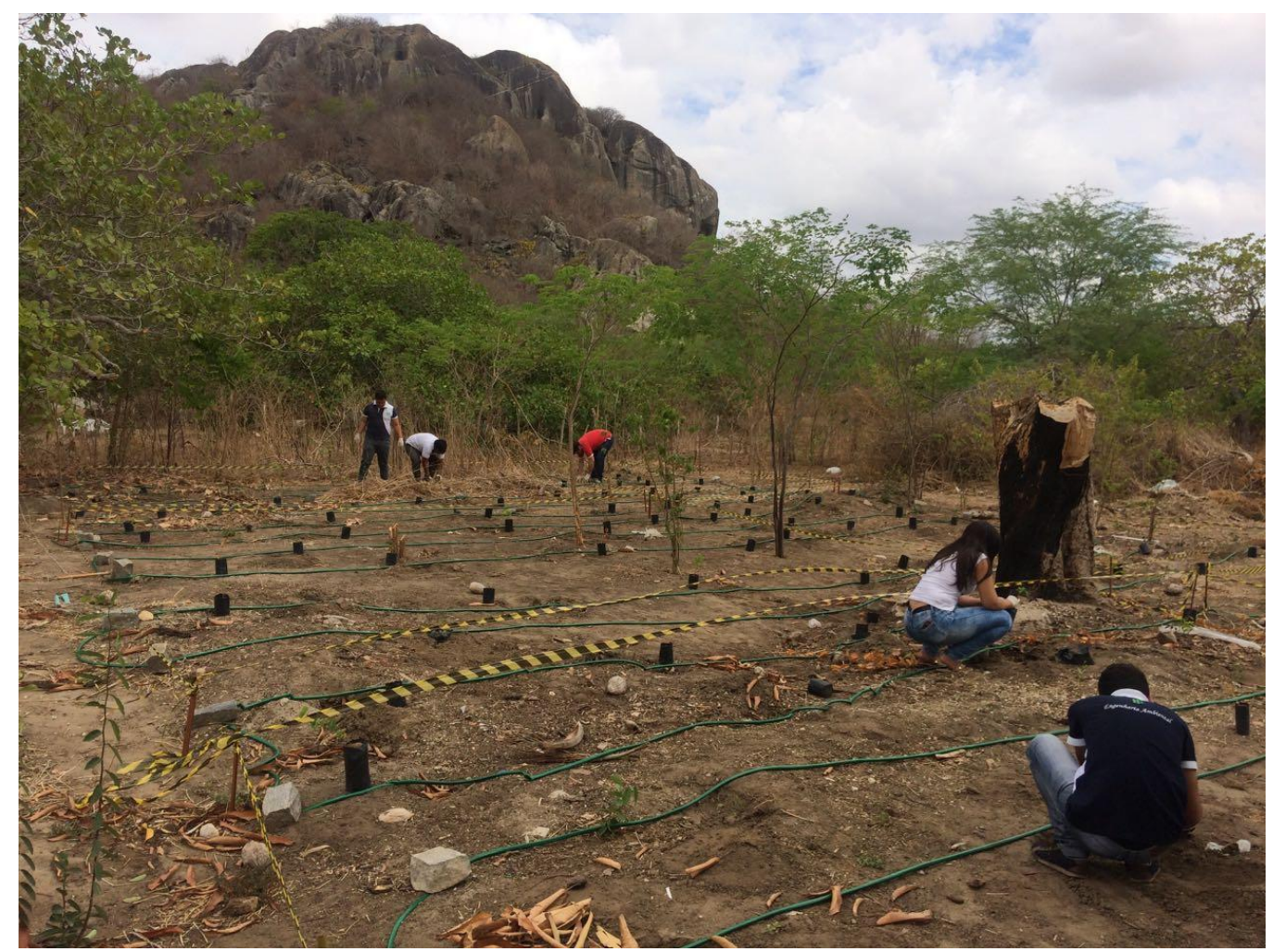

Figura 5: Terceira etapa da mobilização: plantio. Parte 2. 
ISSN- 1413-8638

E-ISSN - 2238-5533

v. 23, n. 3, p. 252-266, 2018

\subsection{Quarta etapa}

Esta etapa é referente ao monitoramento do que foi plantado (Figura 6). Após 3 semanas do plantio, foi verificado que o sistema de irrigação estava com falha e a água não chegava até as covas, resultando em morte de $60 \%$ das 180 mudas que foram plantadas. Esse fato é alarmante pois comprova que se não houver um monitoramento eficiente e um comprometimento da população com a recuperação, o sucesso será inatingível e todo o trabalho terá sido em vão. Após ajustar as falhas, houve replantio dos indivíduos que morreram, e com o monitoramento adequado, apenas $6 \%$ morreram, sendo todos de uma única espécie, a $C$. ferrea. Por ser climácica, essa espécie é bastante exigente de recursos e tem maior dificuldade para se estabelecer num meio degradado (PEREIRA et al., 2012; GALLÃO et al., 2013).

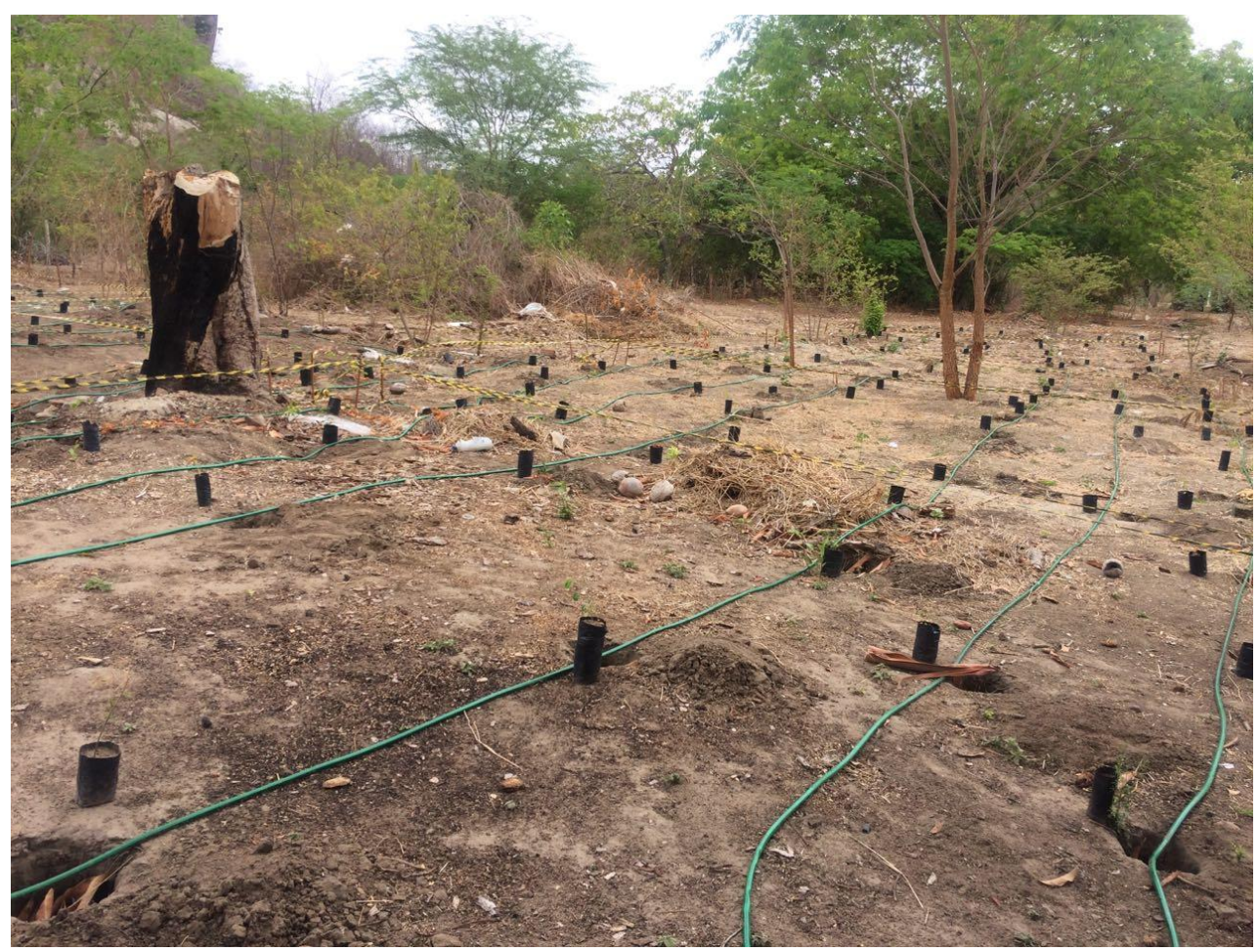

Figura 6: Última etapa da mobilização: monitoramento.

De acordo com estudos realizados por Anten e Sterck (2011) e, Magill, Ashley e Freeman (2012), quando não há disponibilidade adequada de água para as espécies, a maioria destas não conseguem sobreviver por muito tempo, especialmente em sua fase inicial de crescimento. Se houver uma disponibilidade mínima de água, algumas espécies conseguem se adaptar e 
sobreviverem, no entanto, só conseguem após atingir determinado nível de crescimento (XU et al., 2014).

Diante de tudo isso, A classificação mais empregada para distinguir as espécies em grupos funcionais é em pioneiras, secundárias iniciais, secundárias tardias e climácicas (MARTINS, 2009). Sendo as espécies pioneiras caracterizadas por apresentarem um crescimento mais rápido em menor escala temporal, ter densidade de madeira relativamente baixa e com intolerância a sombra, diferindo das secundárias iniciais apenas por apresentar um porte menor (GANDOLFI et al., 1995). Nas secundárias tardias, o crescimento e a densidade de madeira são médios, com tolerância à sombra apenas no estágio juvenil, enquanto as espécies climácicas são mais exigentes de recursos e apresentam crescimento lento, densidade de madeira elevada, alta tolerância a sombra e com um porte mais elevado (JHA e MOHAPATRA, 2009; MARTINS, 2009).

\section{CONCLUSÃO}

De uma forma geral, a comunidade local apresentou baixo interesse em participar de projetos de recuperação de áreas degradadas (RAD), mesmo assumindo as inúmeras vantagens do êxito desses projetos. Além disso, do público-alvo presente, há ausência do domínio de conceitos e definições sobre RAD, bem como de práticas para produção de mudas. No entanto, houve facilidade e eficiência na produção de mudas realizadas pelo público-alvo, comprovando a simplicidade na execução de um projeto de RAD.

Outro fato comprovado, é que um monitoramento inadequado causa insucesso do projeto e a morte dos indivíduos plantados. Por fim, mobilizações como essas despertam o desejo do público-alvo em realizar projetos similares e difundir os conhecimentos adquiridos.

\section{AGRADECIMENTOS}

Este trabalho só pode ser realizado devido a uma parceria da Secretaria de Meio Ambiente (SEMA) com Jardim Botânico do Ceará, localizado em Caucaia. Além disso, todo o fomento foi concedido pelo Projeto Biomas da EMBRAPA. O Instituto Federal de Educação, Ciência e Tecnologia do Ceará, 
IFCE, campus Quixadá, também foi fundamental ao dar todo o suporte para a realização de cada etapa.

\section{REFERÊNCIAS BIBLIOGRÁFICAS}

ALVAREZ, I. A. et al. Arborização urbana no semiárido: espécies potenciais da Caatinga. Colombo, PR, Embrapa Florestas, 2012.

ANDRADE, J. A. P.; ALMEIDA, L. Q. A CONTINUIDADE DA DEGRADAÇÃO NA APA DO ESTUÁRIO DO RIO CEARÁ. Geosaberes, Fortaleza, v. 3, n. 6, p.60-70, dez. 2012.

ANTEN, N. P. R.; STERCK, F. J.. Terrestrial vs aquatic plants: how general is the drag tolerance-avoidance trade-off?. New Phytologist, [s.l.], v. 193, n. 1, p.6-8, dez. 2011.

ARAÚJO, C.S.F.; SOUSA, A.N. Estudo do processo de desertificação na caatinga: uma proposta de educação ambiental. Ciência \& Educação, Campina Grande, v. 17, n. 4, p.975-986, 2011.

AMÉRICO, J. H. P. et al. Condições Ambientais de propriedades agrícolas e percepção ambiental de produtores rurais do município de dobrada - São Paulo, Brasil. Holos Environment, S.i., v. 12, n. 2, p.241-249, out. 2012.

CHAVES, I. B. et al. Modelagem e mapeamento da degradação da caatinga. Revista Caatinga, Mossoró, v. 28, n. 1, p.183-193, mar. 2015.

CONSUEGRA, S. B. M. et al.Effect of the addition of sewage sludge as a fertilizer on a sandy vineyard soil. Journal Of Soils And Sediments. [s.i.], v. 16 (4), p. 1360-1365. mar. 2015.

CORTES-JUNIOR, L. P.; FERNANDEZ, C. Environmental education in chemistry teacher training: a diagnostic study and social representations. Química Nova, [s.I.], p.748-756, 2016.

DOMBROSKI, J.I.d. et al.Water relations of Caatinga trees in the dry season. South African Journal Of Botany, [s.I.], v. 77, n. 2, p.430-434, abr. 2011.

EMADODIN, I.; NARITA, D.; BORK, H. R. Soil degradation and agricultural sustainability: an overview from Iran. Environment, Development and Sustainability, [s.I.], v. 14, n. 5, p.611-625, 25 abr. 2012.

FERRARA, C.; SALVATI, L.; TOMBOLINI, I. An integrated evaluation of soil resource depletion from diachronic settlement maps and soil cartography in peri-urban Rome, Italy. Geoderma, [s.I.], v. 232-234, p.394-405, nov. 2014. 
GALLÃO, M. I. et al. Morphological, chemical and rheological properties of the main seed polysaccharide from Caesalpinia ferrea Mart. Industrial Crops And Products, [s.I.], v. 47, p.58-62, maio 2013.

GALES, D. C. et al.Effects of a hydrogel on the cambic chernozem soil's hydrophysic indicators and plant morphophysiological parameters. Geoderma, [s.I.], v. 267, p.102-111, abr. 2016.

GANDOLFI, Sergllis et al. Levantamento florístico e caráter sucessional das espécies arbustivo-arbóreas de uma floresta mesófila semidecídua no munlcwio de guarulhos, SP. Revista Brasileira de Biologia, [S.i.], v. 55, n. 4, p.753-767, nov. 1995

IBGE - Instituto Brasileiro de Geografia e Estatística, 2010. Mapa de Vegetação Brasil, Disponível em $<\mathrm{ftp}$ ://ftp.ibge.gov.br/Cartas_e_Mapas/Mapas_Murais/biomas_pdf.zip>. Acesso em: 02 abr. 2016.

(IPECE), Instituto de Pesquisa e Estratégia Econômica do Ceará. Perfil Básico Municipal 2015: Quixadá. Ceará: Secretária de Planejamento e Gestão, 2015.

ITURRI, L. A. et al. Comparing adjacent cultivated and "virgin" soils in wind erosion affected environments can lead to errors in measuring soil degradation. Geoderma. [s.i.], p. 42-53. fev. 2016.

JHA, P., MOHAPATRA, K. P. Leaf litterfall, fine root production and turnover in four major tree species of the semi-arid region of India. Plant Soil, 326, p. 481491, 2009.

KHALEDIAN, Y. et al. Assessment and Monitoring of Soil Degradation during Land Use Change Using Multivariate Analysis. Land Degradation Development, [s.l.], p.1-34, maio 2016.

LAPLANE, M. F. et al. Desertificação, degradação da terra e secas no Brasil. Brasília: Centro de Gestão e Estudos Estratégicos, 2016. 256 p.

LEAL, I.R., PERINI, M.A., CASTRO, C.C., 2003. Estudo fenológico de espécies de Euphorbiaceae em uma área de Caatinga. Proceedings of VII Congresso de Ecologia do Brasil, Sociedade de Ecologia do Brasil.

MAGILL, C. R.; ASHLEY, G. M.; FREEMAN, K. H.. Water, plants, and early human habitats in eastern Africa. Proceedings Of The National Academy Of Sciences, [s.l.], v. 110, n. 4, p.1175-1180, dez. 2012.

MARTINS, S.V. Recuperação de áreas degradada: ações em áreas de preservação

permanente, voçorocas, taludes rodoviário e de mineração. Editora Aprenda Fácil, 2009.

MEDEIROS, H. B.; ARAUJO, M. S. S.; PEREIRA, M. R. V. Reciclagem de resíduos sólidos urbanos: uma proposta interdisciplinar de conscientização em 
educação ambiental atrelado a um jogo computacional. Anap Brasil, [s.i.], v. 8, n. 10, p.52-64, 2015.

OLIVEIRA, M. R.; SILVA, G. H.. Determinação da taxa de crescimento das cotações do volume de crédito de carbono praticado no brasil. Revista de Administração de Roraima - Rarr, [s.l.], v. 6, n. 2, p.415-429, 23 dez. 2016.

PEREIRA, L. P. et al. Polysaccharide fractions of Caesalpinia ferrea pods: Potential anti-inflammatory usage. Journal Of Ethnopharmacology, [s.I.], v. 139, n. 2, p.642-648, jan. 2012.

QUINTON, J.. Desertification, Land Degradation and Sustainability. Soil Use and Management, [s.I.], v. 28, n. 4, p.648-648, 22 nov. 2012.

RODRÍGUEZ, A. R.; CAMPILLO, M. C.; MORAGA, E. Q. Beauveria bassiana: An entomopathogenic fungus alleviates Fe chlorosis symptoms in plants grown on calcareous substrates. Scientia Horticulturae, [s.I.], v. 197, p.193-202, dez. 2015.

SALVATI, L. et al. Complex Adaptive Systems, soil degradation and land sensitivity to desertification: A multivariate assessment of Italian agro-forest landscape. Science Of The Total Environment, [s.I.], v. 521-522, p.235-245, jul. 2015.

SILVA, V. E. P. S. G. S. Diversidade da caatinga para arborização urbana no semiárido cearense. In: I CONGRESSO INTERNACIONAL DA DIVERSIDADE DO SEMIÁRIDO, 1, 2016, Campina Grande. Anais. Campina Grande: Realize, 2016. p. 01 - 06.

SILVA, V. E. P. S. G. S.; GADELHA, N.. Uso da valoração como ferramenta na educação ambiental. In: V CONGRESSO BRASILEIRO DE EDUCAÇÃO AMBIENTAL APLICADA E GESTÃO TERRITORIAL, 2016, Fortaleza. Anais. Mossoró: Uern, 2016. p. 145 - 155.

SOUZA, J. C. S.. Working with Environmental Education: the importance of a sewage treatment station in the City of São Leopoldo, Rio Grande do Sul. Boletim do Observatório Ambiental Alberto Ribeiro Lamego, [s.l.], v. 7, n. 2, p.12-27, 2013.

UYANIK, G. Effect of Environmental Education Based on Transformational Learning Theory on Perceptions towards Environmental Problems and Permanency of Learning. International Electronic Journal Of Environmental Education, S.i., v. 6, n. 2, p.126-140, maio 2016.

XU, B. et al. Contribution of NAC Transcription Factors to Plant Adaptation to Land. Science, [s.I.], v. 343, n. 6178, p.1505-1508, mar. 2014. 